\title{
Effect of Periodontal Therapies on Indirect Restoration: A Scanning Electron Microscopic Analysis
}

\author{
Priscilla Barbosa Ferreira SOARES ${ }^{1}$ \\ Denildo MAGALHÃES ${ }^{1}$ \\ Alfredo Júlio FERNANDES NETO² \\ Carolina Guimarães CASTRO ${ }^{3}$ \\ Paulo César Freitas SANTOS FILHO ${ }^{3}$ \\ Carlos José SOARES 3
}

\author{
${ }^{1}$ Department of Periodontology and Implantology, Dental School, \\ Federal University of Uberlândia, Uberlândia, MG, Brazil \\ ${ }^{2}$ Department of Occlusion, Fixed Prosthodontics and Dental Materials, Dental School, \\ Federal University of Uberlândia, Uberlândia, MG, Brazil \\ ${ }^{3}$ Department of Operative Dentistry and Dental Materials, Dental School, \\ Federal University of Uberlândia, Uberlândia, $M G$, Brazil
}

\begin{abstract}
The aim of this study was to evaluate the influence of different periodontal therapies on the integrity of indirect restorations by scanning electron microscopy (SEM). Sixty single-rooted bovine teeth were selected and randomly assigned to 12 groups. Inlay cavities were prepared in the cervical region on the center of the cementoenamel junction, and were restored with laboratory processed resin and luted with a resin cement. Twelve periodontal therapies were used ( $\mathrm{n}=5)$ : $\mathrm{C}$ : control (no treatment); MS: manual scaling with Gracey curettes; US: ultrasonic scaling; PP: prophylaxis with prophylactic paste; PS: prophylaxis with pumice-stone; SBJ: sodium bicarbonate jet; MS/PP; MS/PS; MS/SBJ; US/PP; US/PS; US/SBJ. The specimens were prepared and analyzed by SEM. SEM micrographs at $\times 100$ to $\times 1000$ magnification were obtained from the surface of the laboratory resin and the interface of the indirect restorations. The images were evaluated by 3 skillful, calibrated, blinded observers as to the presence of grooves, microcavities and fracture of margins. The results showed that PS produced groves on restoration surface. MS and US produced groves and marginal fractures on the restorations. SBJ resulted in resin cement degradation. These results suggest that except for PS, all procedures had deleterious effects on the marginal integrity of indirect restorations.
\end{abstract}

Key Words: composite, dental scaling, sodium bicarbonate, dental prophylaxis, scanning electron microscopy.

\section{INTRODUCTION}

The main goal of the treatment of patients with periodontitis is to establish and maintain an adequate infection control in the gingival area (1). Scaling and root planning, combined with effective self-performed supragingival biofilm control measures, attends this purpose by altering the submarginal ecological environment through disruption of the microbial biofilm and suppression of the inflammation (1-3). Dental calculus is calcified dental biofilm, composed primarily of calcium phosphate mineral salts deposited between and within remnants of formerly viable microorganisms. A viable dental plaque covers mineralized calculus deposits (4). The periodic mechanical removal of supra and subgingival microbial biofilm is essential for controlling inflammatory periodontal diseases $(1,3)$. Several procedures can be used to reach this goal, such as scaling with hand curettes and ultrasonic scalers $(4,5)$, prophylaxis (5) and polishing to produce smoother dental surfaces (2). Staining by nicotine or components with high levels of pigmentation and with food staining, on the board of

Correspondence: Prof. Dr. Carlos José Soares, Grupo de Biomecânica, Faculdade de Odontologia, Universidade Federal de Uberlândia, Área de Dentística e Materiais Odontológicos, Avenida Pará, n 1720, Bloco B, 2B24, 38400-902 Uberlândia, MG, Brasil. Tel: +55-34-3218-2255. Fax: +55-34-3218-2279. e-mail: carlosjsoares@umuarama.ufu.br 
the restorations and even the adjacent dental structures are indication for these procedures (6).

An indirect restoration involves, for esthetic reasons, subgingival cavity preparation, which can be considered as a complication factor to promote a smooth root surface. The alteration of marginal adaptation can become a cofactor in biofilm accumulation and failure of periodontal therapy $(2,7)$. Studies have compared conventional methods used in periodontal therapies to remove subgingival biofilm and calculus together with the cementum contaminated by bacterial products (5), loss of dental tissue and restorative material $(2,3)$, roughness surface $(8)$ and poor marginal adaptation (9), showing different responses for the parameters described above.

In this context, is hypothesized that different periodontal therapies affect the marginal integrity and surface of indirect restorations in the gingival area. The aim of this study was to evaluate, by scanning electron microscopy, the surface integrity of indirect restorations fabricated with laboratory processed resin in the cervical region after manual scaling after use of several combined therapies.

\section{MATERIAL AND METHODS}

Sixty freshly extracted bovine incisors were selected for this study. The teeth were stored in $0.2 \%$ thymol solution (Pharmacia Biopharma Ltda., Uberlândia, $\mathrm{MG}, \mathrm{Brazil})$ at $37^{\circ} \mathrm{C}$ and randomly divided into 12 groups $(n=5)$. The soft tissue deposits were removed with a hand scaler (Hu-Friedy, Chicago, IL, USA), and the teeth were cleaned using a rubber cup and fine pumice water slurry.

The root portion of each tooth was sectioned 15.0 $\mathrm{mm}$ from the root apex with a double-faced diamond disk (KG Sorensen, Barueri, SP, Brazil) in a slow-speed handpiece (KaVo do Brasil Ltda, Joinville, SC, Brazil), under copious water spray. Then, the teeth were mounted individually in plastic cylinders with a diameter of 20.0 mm (Tigre, São Paulo, SP, Brazil) embedded in a polystyrene resin (Cristal, Piracicaba, SP, Brazil), exposing the buccal surface. Standardized cavities were prepared with \#3131 diamond burs (KG Sorensen) mounted in a cavity preparation machine (Federal University of Uberlândia, Uberlândia, MG, Brazil). Preparations were done on the buccal surface, reaching the cementoenamel junction, with the following standardized dimensions: $4.0 \mathrm{~mm}$ cervico-incisal width; $3.0 \mathrm{~mm}$ mesiodistal width and $2.0 \mathrm{~mm}$ depth.

A single-stage impression was made of each prepared tooth using polyether-based impression material (Impregum Soft; 3M/ESPE, St. Paul, MN, USA). The impression was poured with type IV stone (Durone IV; Dentsply Caulk, Milford, DE, USA) and the stone model was numbered in reference to the original numbering of the teeth. The laboratory-processed resin restorations (SR Adoro system; Ivoclar Vivadent, Schaan, Liechtenstein) were fabricated using, initially, a resin liner layer (SR Adoro liner 200; Ivoclar Vivadent), which was polymerized in a special unit (Targis Quick; Ivoclar Vivadent) for $15 \mathrm{~s}$. Next, 1-mm increments of dentin shade resin (A3 shade, SR Adoro; Ivoclar Vivadent) were placed in the die, and each one was polymerized in the same processing unit (Targis Quick; Ivoclar Vivadent) for $15 \mathrm{~s}$. This was followed by light polymerization for $25 \mathrm{~m}$ at $95^{\circ} \mathrm{C}$ in another processing unit (Targis Power; Ivoclar Vivadent).

After $24 \mathrm{~h}$, the intaglio surface of the laboratory processed resin restoration was airborne-particle abraded with $50-\mu \mathrm{m}$ particle aluminum oxide for $10 \mathrm{~s}$ at a distance of $1.0 \mathrm{~cm}$, washed with water-air spray for $60 \mathrm{~s}$, air-dried, and then a silane bonding agent (Ceramic Primer; 3M/ ESPE) was applied for $60 \mathrm{~s}$. Each cavity was etched with $37 \%$ phosphoric acid (3M/ESPE) for $15 \mathrm{~s}$, washed with water spray for $15 \mathrm{~s}$, and dried with absorbent paper. Two layers of a single-bottle adhesive system (Single Bond 2; 3M/ESPE) were applied with an interval of 20 $\mathrm{s}$ and light cured for $20 \mathrm{~s}$ with a halogen light unit with an intensity of $800 \mathrm{~mW} / \mathrm{cm}^{2}$ (XL 3000; 3M/ESPE). The restorations were luted with a dual-polymerized resin cement (RelyX ARC; 3M/ESPE). Digital pressure was applied, the excess cement was removed and the material was light cured with the halogen unit with $800 \mathrm{~mW} /$ $\mathrm{cm}^{2}$ (XL-3000; 3M/ESPE) for $40 \mathrm{~s}$. All restorations were finished and polished $48 \mathrm{~h}$ after fixation using sequential Sof-Lex discs (3M/ESPE). The teeth were stored in distilled water at $37^{\circ} \mathrm{C}$ for $24 \mathrm{~h}$.

All specimens were subjected to different periodontal protocols involving the restoration area $\mathrm{C}$ : control (no periodontal treatment); MS: manual scaling with Gracey curettes 5/6 (Hu-Friedy, Chicago, IL, USA), totalizing 10 instrumentation cycles in a cervical-incisal direction; US: ultrasonic scaling (Jet Sonic Total; Gnatus, Ribeirão Preto, SP, Brazil), totalizing 10 instrumentation cycles in a cervical-incisal direction; PP: prophylaxis with a fine prophylactic paste (Herjos-F; Vigodent S.A., Rio de Janeiro, RJ, Brazil), using a rubber cup coupled 
to a slow-speed handpiece (KaVo) under copious water spray totalizing $15 \mathrm{~s}$; PS: prophyaxis with fine pumicestone (S.S. White, Rio de Janeiro, RJ, Brazil) diluted in saline (Sanobiol, Pouso Alegre, MG, Brazil). The water/ powder proportion of the paste was standardized in order to obtain a hard consistency, which allowed dispersion of the material on the surface during application. The pumice paste was applied with a rubber cup, coupled to a slow-speed handpiece, directly on the surfaces during $15 \mathrm{~s}$; SBJ: sodium bicarbonate jet (Jet Sonic Total; Gnatus) was applied at $5.0 \mathrm{~mm}$ from the surface and with the nozzle orifice positioned at $90^{\circ}$, during $15 \mathrm{~s}$; MS/PP: manual scaling followed by prophylaxis with a fine prophylactic paste during $15 \mathrm{~s}$; MS/PS: manual scaling followed by prophylaxis with fine pumice-stone during $15 \mathrm{~s}$; MS/SBJ: manual scaling followed by sodium bicarbonate jet during $15 \mathrm{~s}$. US/PP: ultrasonic scaling followed by prophylaxis with a fine prophylactic paste during $15 \mathrm{~s}$; US/PS: ultrasonic scaling followed by prophylaxis with fine pumice-stone during $15 \mathrm{~s}$; US/SBJ: ultrasonic scaling followed by sodium bicarbonate jet during $15 \mathrm{~s}$. After the periodontal treatments, the surfaces received an air/water spray for $20 \mathrm{~s}$.

Aiming at standardization, the periodontal procedures were done by a single operator. Using a double-faced diamond disc (KG Sorensen) at high speed and under air-water spray cooling, 5 cross-sections were obtained from the buccal surface of each tooth at a distance of $2 \mathrm{~mm}$ from the margins of the restoration. The specimens were cleaned in an ultrasonic device with distilled water during $10 \mathrm{~min}$. Next, they were fixed in $2.0 \%$ glutaraldehyde (Pharmacia Biopharma Ltda., Uberlândia, $\mathrm{MG}$, Brazil) for $15 \mathrm{~h}$ at $4{ }^{\circ} \mathrm{C}$, washed three times in distilled water, dehydrated in alcohol (Pharmacia Biopharma Ltda.) at concentrations of $50 \%, 70 \%$ and $95 \%$ for $10 \mathrm{~min}$ each and at the $100 \%$ concentration $100 \%$ for $30 \mathrm{~min}$. After storage in an oven inside a receptacle containing silica for $8 \mathrm{~h}$ to remove moisture, the specimens were mounted on an aluminum stub (one stub per group), sputter-coated with a thin layer of gold, and examined with a scanning electron microscope (LEO 435 VP; Carl Zeiss, Germany/ NAPMEPA-ESALQ-USP). SEM micrographs were obtained from each specimen at $\times 100-5000$ magnifications in different areas: restoration, resin cement and root dentin.

The SEM micrographs were presented as digital images to 3 skillful, calibrated, blinded observers. A standard error of the mean of 0.062 was considered for intraexaminer and interexaminer calibration. Data were recorded in a worksheet that had on one side the periodontal protocols and on the other side the following evaluation criteria: grooves, microcavities and fracture of margins.
Table 1. Distribution (\%) of the studied criteria for each periodontal treatment evaluated.

\begin{tabular}{|c|c|c|c|c|c|c|c|c|c|}
\hline \multirow{2}{*}{$\begin{array}{l}\text { Periodontal } \\
\text { protocols }\end{array}$} & \multicolumn{3}{|c|}{ Restoration } & \multicolumn{3}{|c|}{ Resin cement } & \multicolumn{3}{|c|}{ Root surface } \\
\hline & $\mathrm{G}$ & $\mathrm{M}$ & $\mathrm{Fm}$ & $\mathrm{G}$ & $\mathrm{M}$ & $\mathrm{Fm}$ & $\mathrm{G}$ & $\mathrm{M}$ & $\mathrm{Fm}$ \\
\hline $\mathrm{C}$ & - & - & - & - & - & - & - & - & - \\
\hline MS & 100 & - & 40 & 20 & 40 & 60 & 100 & - & 60 \\
\hline US & - & - & - & - & 40 & - & - & - & - \\
\hline PP & - & - & - & - & - & - & - & - & - \\
\hline PS & 80 & - & - & 20 & 60 & - & 100 & - & - \\
\hline SBJ & 10 & - & - & - & 50 & - & 10 & 10 & - \\
\hline MS/PP & 80 & - & 50 & 30 & 50 & 50 & 90 & - & 50 \\
\hline MS/PS & 100 & - & 40 & - & 60 & 50 & 100 & - & 60 \\
\hline $\mathrm{MS} / \mathrm{SBJ}$ & 90 & - & 50 & - & 60 & 40 & 100 & - & 50 \\
\hline US/PP & - & - & - & - & 50 & - & - & - & - \\
\hline US/PS & 20 & - & - & 20 & 60 & - & 100 & - & - \\
\hline US/SBJ & 20 & - & - & - & 50 & - & 20 & 20 & - \\
\hline
\end{tabular}

G: grooves, M: microcavities, Fm: fracture of margins. C (control group): no treatment; MS: manual scaling with Gracey curette; US: ultrasonic scaling; PP: prophylaxis with prophylactic paste; PS: prophylaxis with pumice-stone; SBJ: sodium bicarbonate jet; MS/PP: manual scaling followed by prophylaxis with prophylactic paste; MS/PS: manual scaling followed by prophylaxis with pumicestone; MS/SBJ: manual scaling followed by sodium bicarbonate jet; US/PP: ultrasonic scaling followed by prophylaxis with prophylactic paste; US/PS: ultrasonic scaling followed by prophylaxis with fine pumice-stone; US/SBJ: ultrasonic scaling followed by sodium bicarbonate jet. 


\section{RESULTS}

The percent distribution of the evaluation criteria for each periodontal treatment is presented in Table 1. The SEM analysis showed that all proposed treatments changed all surfaces of the restoration, interface and dental structures, when compared to the control group (Fig. 1). SBJ resulted in degradation of the cement line, creating porosities and an irregular surface, forming a gap at the tooth-restoration interface (level 2) (Fig. 2). PS caused groves on the restoration and tooth surfaces (level 2) (Fig. 3). PP alone did not affect the integrity of the structures (Fig. 4). The use of MS (Fig. 5A) promoted more marginal fractures and groves on all surfaces than US (level 3) (Fig. 6A). However, no roughness surface alteration was found for MS/SBJ (Fig. 5B) and US/ SBJ (Fig. 6B) groups. PS/MS and PS/US increased the deleterious effects on different surfaces (Fig. 5C and Fig. 6C). PP/Ms and PP/US (Fig. 5D and Fig 6D).

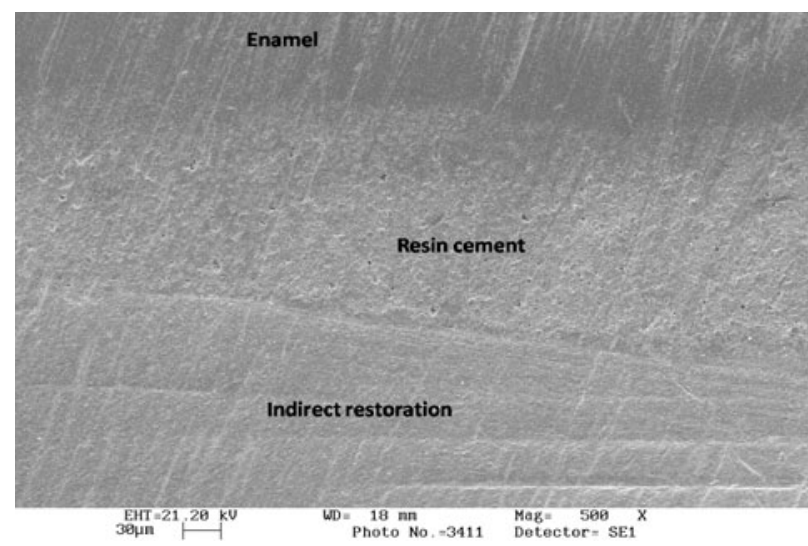

Figure 1. Schematic presentation of specimen preparation.

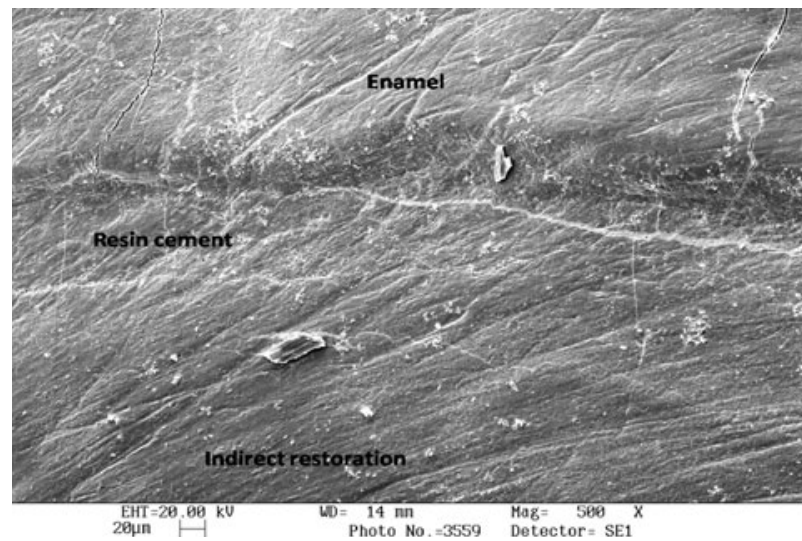

Figure 3. Prophylaxis with fine pumice-stone diluted in saline.

\section{DISCUSSION}

The hypothesis tested in this study was partially accepted, as the different periodontal protocols modified the surface and the marginal integrity of indirect laboratory resin restoration at different levels, except for prophylaxis with prophylactic paste. The degradation of the restorative materials may increase the roughness and cause damage of margins, structural weakening or even loss of the restoration (2). The clinical consequences from microfractures on restoration margins are clinically visible only in few cases. Therefore, in vitro studies are necessary to determine the effects caused by the instruments used during periodontal therapy and maintenance therapy. SEM has been referred to an adequate method that has also given valuable information about surface morphology $(3,5,8,10-12)$.

When comparing manual and ultrasonic scaling, it appears that the ultrasound (Fig. 6) produced smoother

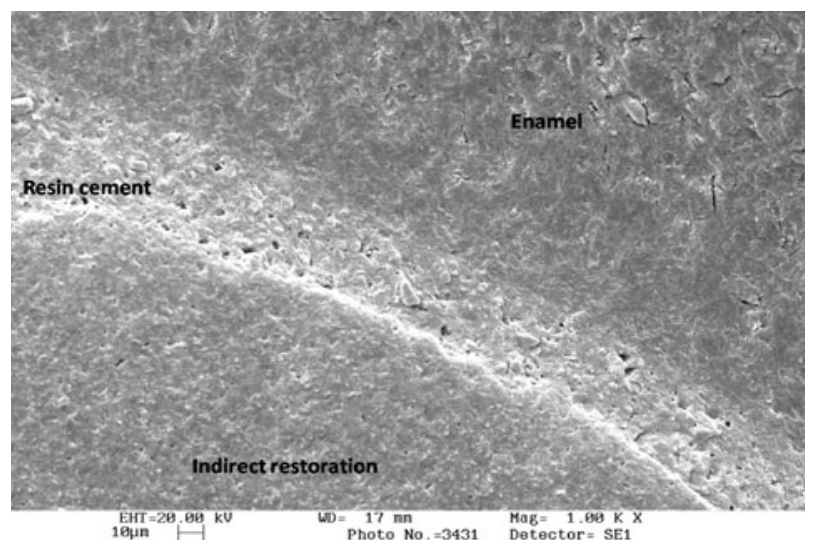

Figure 2. Sodium bicarbonate jet.

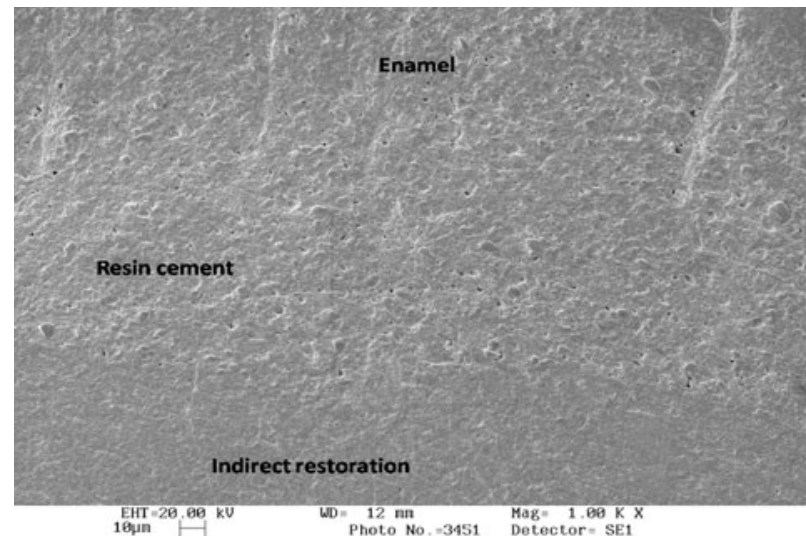

Figure 4. Prophylaxis with a fine prophylactic paste. 
surfaces than the manual curettes (Fig. 5). Both created parallel grooves and marginal fractures, which were more evident in the manually scaled specimens. Some studies of SEM analysis observed similar results with more irregular surfaces and cavitations in specimen scaled with curettes (10-13).

Some authors $(3,13-17)$ have reported the need of periodontal procedures to remove infected dental structure, aiming at recovering the periodontal health and tissue biocompatibility. However, a study in dogs (14) showed that the removal of contaminated cementum is not necessary for the success of periodontal therapy. A clinical study in humans (15) suggested that the removal of the root cementum for eliminating endotoxins was possibly not necessary for achieving periodontal health (15). Therefore, the instrumentation should rather be performed with instruments that effectively remove biofilm and calculus, and cause minimum removal of tooth structure. In the same way as previous studies,
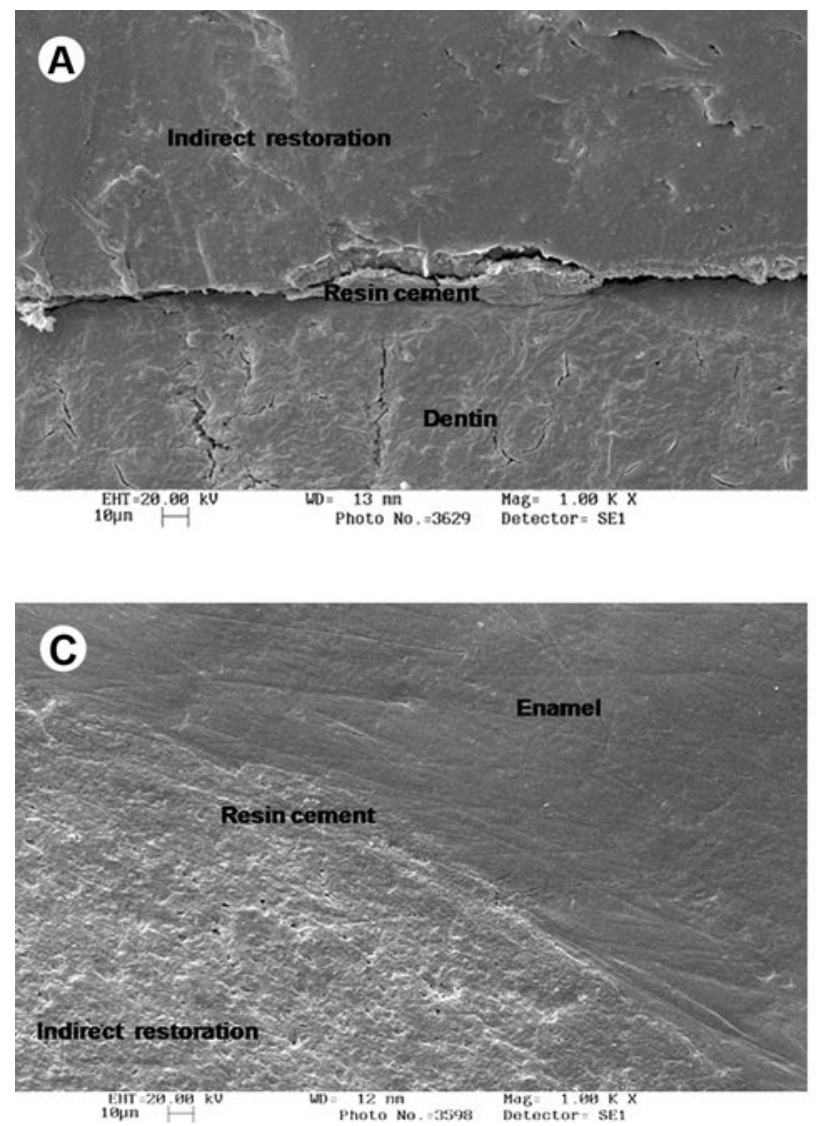

Figure 5. Association of periodontal therapies: (A) manual scaling with Gracey curette; (B) manual scaling followed by sodium bicarbonate jet; (C) manual scaling followed by prophylaxis with fine pumice-stone diluted in saline solution; (D) manual scaling followed by prophylaxis with prophylactic paste.
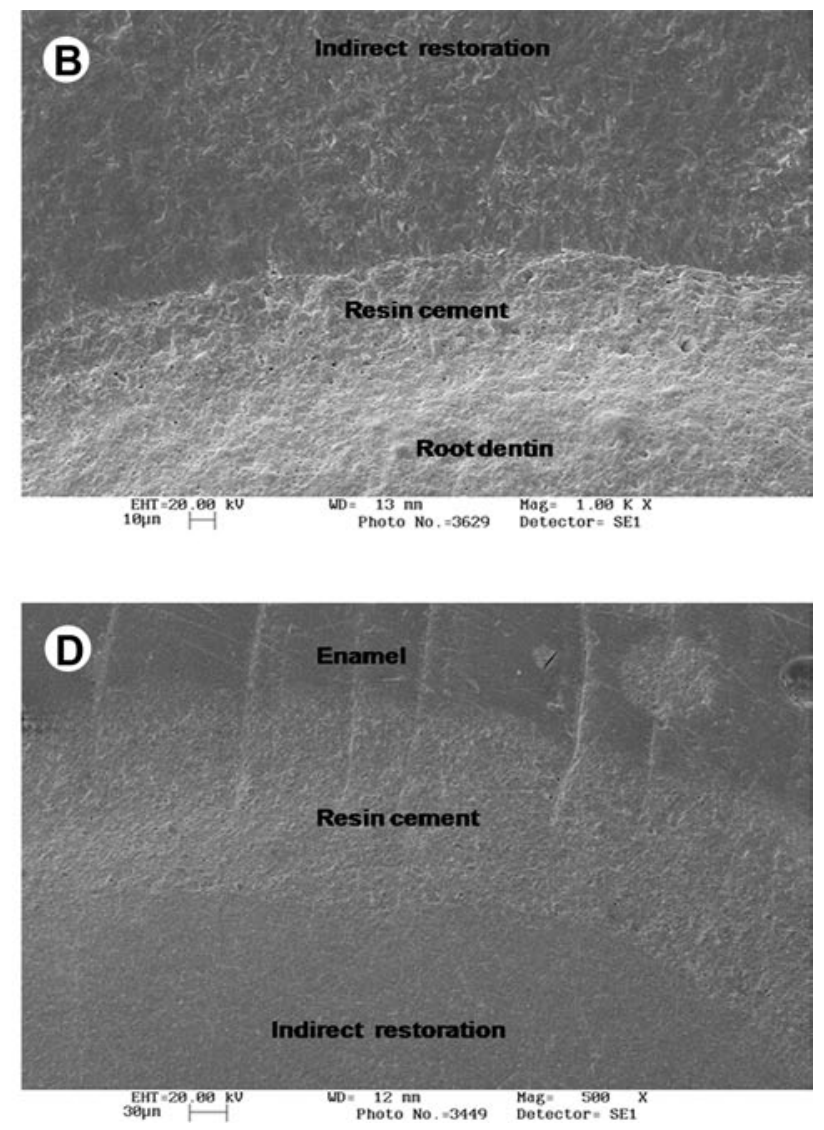

other investigations have compared manual instruments to sonic and ultrasonic devices regarding to root substance removal showing favorable results to the use of ultrasonic scaling $(16,17)$.

The elimination of the dental biofilm deposited on root surface using periodontal prophylaxis, rather than the removal of cementum, is essential for accomplishing periodontal health following therapy promoting biofilm disorganization (5). Treatment with sodium bicarbonate jet is efficient and convenient for plaque removal and extrinsic staining deposited on tooth structure. Although this treatment produces biofilm-free tooth surfaces, the results of this study confirmed that the use of sodium bicarbonate caused accentuated root erosion and degradation of the restoration and resin cement (8). Some authors $(1,6,18)$ have suggested limiting the use of this technique in patients with advanced periodontal disease, where denuded root surfaces are frequently found. Another prophylactic technique is the association of 
pumice stone and saline solution, which is considered less effective in dental biofilm removal than sodium bicarbonate jet $(2,5)$. The SEM analysis showed that this procedure produced grooves on the tooth and restorative material due the high abrasive consistency. Prophylaxis with prophylactic paste resulted in no apparent effect on the analyzed structures. This behavior could be explained by the presence of less abrasive components (pumice stone, calcium carbonate, sodium lauryl sulfate or similar materials in its formulation). In addition this procedure has the ability to polish the tooth and restoration surfaces $(4,8)$. Prophylaxis with prophylactic paste presented better performance than the other protocols tested in this study. The deleterious effects observed after manual and ultrasonic protocols were partial eliminated when prophylactic paste was used after scaling. This fact was not observed in the other associations analyzed in this study, which produced enhanced grooves, marginal fractures of the restoration and deterioration of the cement line.

Within the limitations of this study and based on the methodology employed, it can be concluded that root planning with manual scaling resulted in a larger number of groves on tooth and restoration surfaces and marginal fractures of restorations than ultrasonic scaling. Prophylaxis with pumice stone promoted groves on restorations and dental structures, and the use of sodium bicarbonate jet promoted degradation of the restoration and mainly on the resin cement, thus forming a gap at the tooth-restoration interface.

\section{RESUMO}

O objetivo desse estudo foi avaliar a influência de diferentes terapias periodontais na integridade de restaurações indiretas por meio de microscopia eletrônica de varredura (MEV). Sessenta raízes bovinas foram selecionadas e aleatoriamente divididas em 12 grupos. Preparos cavitários inlay foram realizados na região cervical central da junção cemento-esmalte e restaurados com
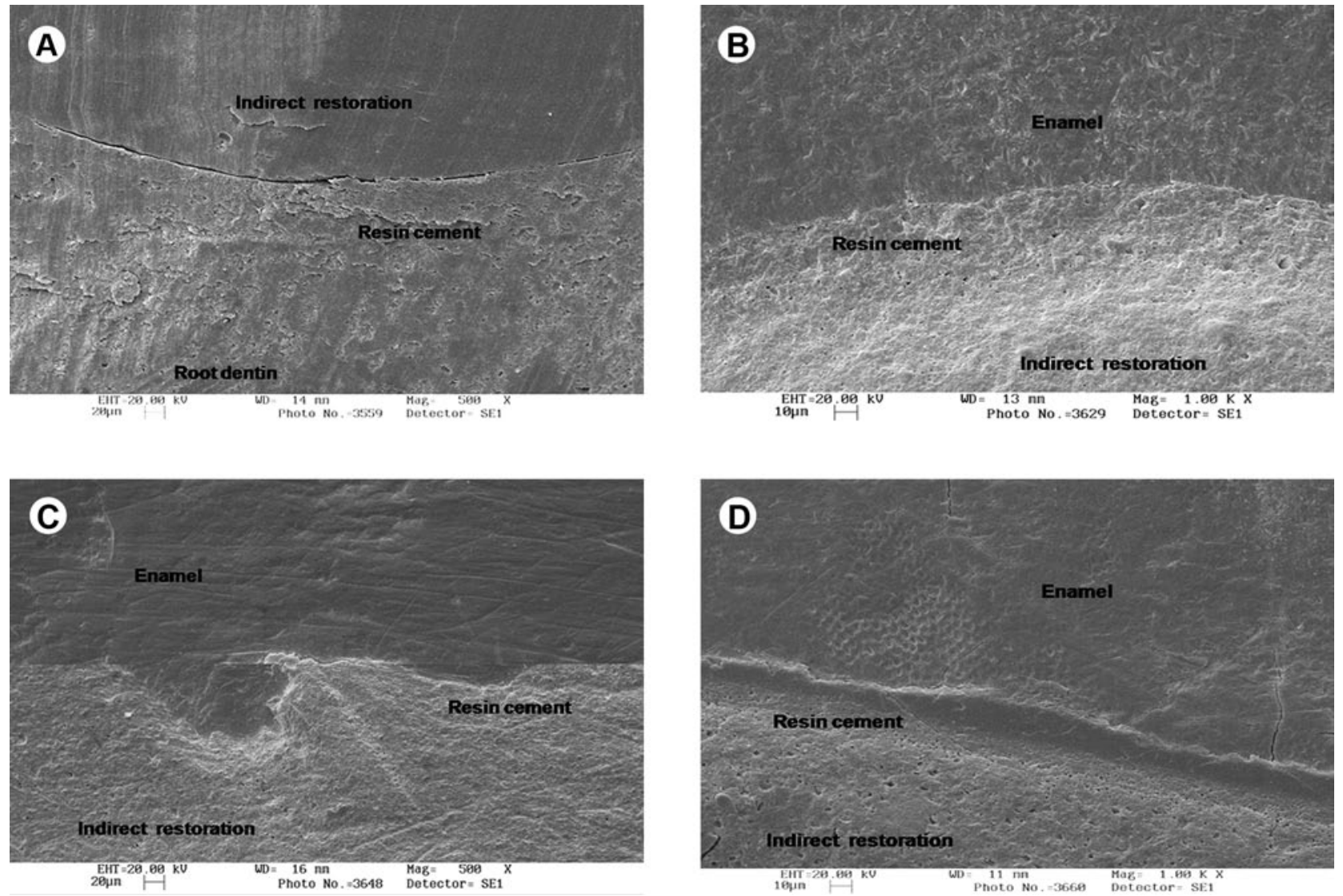

Figure 6. Association of periodontal therapies: (A) ultrasonic scaling; (B) ultrasonic scaling followed by sodium bicarbonate jet; (C) ultrasonic scaling followed by prophylaxis with fine pumice-stone diluted in saline solution; (D) ultrasonic scaling followed by prophylaxis with prophylactic paste. 
resina laboratorial cimentado com cimento resinoso. Doze terapias periodontais foram usadas $(\mathrm{n}=5)$ : $\mathrm{C}$-sem tratamento (controle); MS-raspagem manual com cureta Gracey; US-raspagem com ultra-som; PP- profilaxia com pasta profilática; PS-profilaxia com pedra pomes; SBJ-jato de bicarbonato; MS/PP; MS/PS; MS/SBJ; US/PP; US/PS; US/SBJ. As amostras foram preparados e submetidas a MEV. Imagens, de $\times 100$ a $\times 1000$, da superfície da resina laboratorial e da interface das restaurações indiretas foram obtidas. As imagens foram avaliadas em procedimento cego por 3 observadores habilitados previamente calibrados seguindo os seguintes critérios: ranhuras, microcavidades e fratura de margem. Os resultados mostraram que a profilaxia com pedra pomes promoveu ranhuras na superfície das restaurações. Raspagem manual e ultrasônica promoveram ranhuras e fratura de margem das restaurações. Jato de bicarbonato resultou em degradação de cimento resinoso. Os resultados sugeriram que, exceto a profilaxia com pasta profilática, todos os procedimentos resultaram em efeitos deletérios na integridade da margem das restaurações indiretas.

\section{ACKNOWLEDGEMENTS}

The authors are indebted to Prof. EW Kitajima (NAP/MEPA-ESALQ/USP) for technical support in scanning electron microscopy. The authors also acknowledge FAPEMIG for the financial support.

\section{REFERENCES}

1. Wennstrom JL, Tomasi C, Bertelle A, Dellasega E. Full-mouth ultrasonic debridement versus quadrant scaling and root planing as an initial approach in the treatment of chronic periodontitis. $\mathrm{J}$ Clin Periodontol 2005;32:851-859.

2. Ruhling A, Wulf J, Schwahn C, Kocher T. Surface wear on cervical restorations and adjacent enamel and root cementum caused by simulated long-term maintenance therapy. J Clin Periodontol 2004;31:293-298.

3. Rees JS, Addy M, Hughes J. An in vitro assessment of the dentine lost during instrumentation using the Periosonic system. J Clin Periodontol 1999;26:106-109.

4. White DJ. Dental calculus: recent insights into occurrence, formation, prevention, removal and oral health effects of supragingival and subgingival deposits. Eur J Oral Sci 1997;105:508-522.

5. Breininger DR, O'Leary TJ, Blumenshine RV. Comparative effectiveness of ultrasonic and hand scaling for the removal of subgingival plaque and calculus. J Periodontol 1987;58:9-18.

6. Petersilka GJ, Bell M, Häberlein I, Mehl A, Hickel R, Flemmig TF. In vitro evaluation of novel low abrasive air polishing powders. $\mathrm{J}$ Clin Periodontol 2003;30:9-13.

7. van Dijken JW, Sjostrom S. Development of gingivitis around aged restorations of resin-modified glass ionomer cement, polyacidmodified resin composite (compomer) and resin composite. Clin Oral Investig 1998;2:180-183.

8. Salami D, Luz MA. Effect of prophylactic treatments on the superficial roughness of dental tissues and of two esthetic restorative materials. Braz Oral Research 2003;17:63-68.

9. Amiri-Jezeh M, Rateitschak E, Weiger R, Walter C. The impact of the margin of restorations on periodontal health--a review. Schweiz Monatsschr Zahnmed 2006;116:606-613.

10. Casarin RC, Ribeiro FV, Sallum AW, Sallum EA, Nociti-Jr FH, Casati MZ. Root surface defect produced by hand instruments and ultrasonic scaler with different power settings: an in vitro study. Braz Dent J 2009;20:58-63.

11. D’Silva IV, Nayak RP, Cherian KM, Mulky MJ. An evaluation of the root topography following periodontal instrumentation - a scanning electron microscopic study. J Periodontol 1979;50:283-290.

12. Garnick JJ, Dent J. A scanning electron micrographical study of root surfaces and subgingival bacteria after hand and ultrasonic instrumentation. J Periodontol 1989;60:441-447.

13. Ioannou I, Dimitriadis N, Papadimitriou K, Sakellari D, Vouros I, Konstantinidis A. Hand instrumentation versus ultrasonic debridement in the treatment of chronic periodontitis: a randomized clinical and microbiological trial. J Clin Periodontol 2009;36:132-141.

14. Nyman S, Sarhed G, Ericsson I, Gottlow J, Karring T. Role of "diseased" root cementum in healing following treatment of periodontal disease. An experimental study in the dog. J Periodontal Res 1986;21:496-503.

15. Nyman S, Westfelt E, Sarhed G, Karring T. Role of “diseased” root cementum in healing following treatment of periodontal disease. A clinical study. J Clin Periodontol 1988;15:464-468.

16. Schmidlin PR, Beuchat M, Busslinger A, Lehmann B, Lutz F. Tooth substance loss resulting from mechanical, sonic and ultrasonic root instrumentation assessed by liquid scintillation. J Clin Periodontol 2001;28:1058-1066.

17. Busslinger A, Lampe K, Beuchat M, Lehmann B. A comparative in vitro study of a magnetostrictive and a piezoelectric ultrasonic scaling instrument. J Clin Periodontol 2001; 28:642-649.

18. Petersilka GJ, Bell M, Mehl A, Hickel R, Flemmig TF. Root defects following air polishing. J Clin Periodontol 2003;30:165-170.

Accepted March 29, 2010 